\title{
Informalización y privatización del control social: respuestas al miedo a la violencia delictiva*
}

ALEXIS ROMERO SALAZAR**

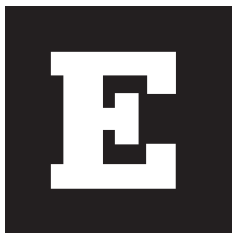

I auge de la violencia delictiva experimentado en el país ha tenido importantes repercusiones en la vida cotidiana de los venezolanos. Se ha producido un incremento de la tasa de homicidios, que se triplicó al pasar de 4,1 en 1986 a 13,5 en 1996. Igualmente, durante esos diez años, aumentaron en 6,58\% los robos a mano armada (Pérez Perdomo et al., 1997).

En este problema lo verdaderamente relevante es el aumento de la letalidad de las agresiones (Briceño-León, 1997), que le daría base real al sentimiento de inseguridad que se extiende por la sociedad; sobre todo por la ausencia de respuestas institucionales en el campo del control social, tanto en lo que respecta al sistema judicial como al aparato policial. Densos sectores de la población han ido optando por salidas privadas de protección, como el cierre de los espacios privados, la contratación de vigilantes o la afiliación a organizaciones ilegales que ofrecen seguridad de bienes.

La vigilancia privada informal, que pudiera constituir una alternativa fundamental para los sectores medios y altos, ya no trata del establecimiento de un convenio entre una empresa prestadora del servicio y cualquier individualidad o grupo que intenta a través de aquel proteger intereses estrictamente económicos. El proceso que aquí se designa como guachimanismo, va más allá de la policía privada que es definida como

\footnotetext{
* El proyecto cuyos resultados fundamentan este articulo formó parte del Programa de Investigación “Construcción Social del Miedo y Mecanismos de Autodefensa", dirigido por el autor y financiado por el CONDES de la Universidad del Zulia.

**Sociólogo, con maestría y estudios doctorales en Sociología del Desarrollo. Profesor Titular de la Universidad del Zulia, Venezuela. E-mail: romeros@cantv.net
} 
un fenómeno corporativo que actúa como policía del capital, es iniciada y financiada por él. Como control social del capital, actúa bajo su autoridad, dirección y sirve a sus intereses más que a los del Estado, aun cuando en algún momento pueda haber coincidencia entre los intereses de ambos; pero en caso de contradicción prevalecerán los intereses particulares (Morais, 1999, p. 31).

Pese a las semejanzas, el guachimanismo - que consiste en la contratación de un vigilante o celador, que recibe el nombre de guachimán ${ }^{1}$ - es un proceso en cuyo origen está el sentimiento de inseguridad de los vecinos (generalmente de un conjunto residencial cerrado), que a través de los administradores o gestores de sus organizaciones comunitarias pagan los servicios de tales personas.

Con el cierre de los espacios residenciales se trata de impedir el contacto con la delincuencia mediante el amurallamiento, creando fortificaciones en las cuales vidas y bienes quedan resguardadas.

Podría señalarse que ambas (contratación de vigilantes informales y privatización de espacios) constituyen formas benignas del control, independientemente del posible impacto de la segregación social.

No se diría lo mismo de la afiliación a organizaciones ilegales que protegen vehículos, si se consideran el terrorismo con el cual previenen el robo y la violencia que caracteriza la recuperación. Ello es así en la medida en que, por lo general, constituyen grupos delincuenciales que actúan gracias al vacío de respuestas oficiales al problema.

El propósito de los tres mecanismos mencionados no es más que reducir el riesgo de los atentados contra la vida y el aseguramiento de algunos bienes, dentro de los cuales los vehículos son emblemáticos (Romero Salazar, 1999).

1 GUACHIMÁN: Hombre que hace la vigilancia de un lugar, como por ej. una casa en construcción, una finca o una fábrica, generalmente por las noches o cuando está deshabitada o solitaria. NÚNÉEZ, R. y PEREZ, F. J. Diccionario del habla actual de Venezuela. Caracas: UCAB, 1994, p. 509. 
Estas modalidades de protección son concretadas por las capas medias de la sociedad, carentes de los recursos para financiar servicios empresariales de seguridad, en general, provistos de tecnología sofisticada, tanto desde el punto de vista comunicacional como de armamentos.

En consecuencia, no es posible estudiar el fenómeno dentro de una concepción clásica del control social, a partir de la cual éste va a ser entendido como aquella serie de mecanismos que expresan un determinado sistema de valores, y que buscan la integración y la cohesión social de los individuos (Melossi, 1987).

Los mecanismos de autoprotección no están referidos a una política comunitaria que toma la prevención en función del ejercicio del control informal de tipo socializador, en la cual el individuo desviado es considerado como el objetivo principal de la intervención. Más bien, se refieren a la expectativa de la disminución del riesgo de que situaciones relacionadas con la violencia delincuencial afecten la esfera privada. Por lo tanto, su ejercicio no está asociado - al menos abiertamente - a la búsqueda de la conformidad de la conducta desviada hacia pautas o normas sociales determinadas. Mucho más si se toma en cuenta que tales mecanismos se activan como medida particular autoprotectiva en función de una percepción de riesgo.

Esto es perfectamente explicable en el contexto social en el que se están desarrollando: el problema de la violencia en Venezuela está asociado al estado de anomia imperante, que se relaciona - como se ha dicho - con la ineficacia del sistema penal, los niveles de impunidad, las profundas contradicciones sociales y las crisis económicas y políticas, que propician la implementación de prácticas de protección desvinculadas de cualquier sentimiento de cociudadanía.

Hay que insistir - en tanto buscan explícitamente evitar el riesgo de que la delincuencia produzca alteraciones en la vida privada -, que estas formas de protección están caracterizadas básicamente por su instrumentalidad. 


\section{Tres enfoques para interpretar las nuevas modalidades del control social}

El fenómeno puede ser insertado en el amplio tema del control social, en el cual están contenidos, en primer lugar, todos los procesos y métodos a través de los cuales una sociedad asegura que sus miembros se ajusten a sus expectativas (al interés general), y en segundo lugar, las respuestas hacia las conductas desviadas. Sin embargo, dadas las características que presenta, se hace necesaria su ubicación en un contexto más específico que posibilite un abordaje teórico más acorde.

Tanto el servicio informal de seguridad privada como el cierre de los espacios residenciales y la afiliación a organizaciones que ofrecen seguridad de bienes, pueden considerarse como mecanismos de autodefensa, implementados por los sectores medios de la sociedad (que tienen acceso a ciertos recursos, pero que no son suficientes para financiar servicios empresariales de seguridad o medios de tecnología sofisticada), con el objetivo de asegurar una cierta protección. Su puesta en práctica está relacionada con las siguientes cuestiones: a) el temor de los individuos de verse afectados por conductas disruptivas, en su integridad personal y sus bienes; b) tales mecanismos constituyen alternativas de iniciativa privada, que de alguna manera son inducidas por la percepción de una situación de violencia generalizada, en la cual la acción de la delincuencia tiene repercusiones inmediatas en su calidad de vida y c) responden a un determinado estilo de vida y posición socioeconómica, de acuerdo a lo cual los individuos se exponen a situaciones de riesgo en forma diferenciada, que buscan anticipar mediante estrategias de prevención también diferenciadas.

Se trata de mecanismos de auto defensa asociados fundamentalmente al miedo hacia la violencia delincuencial, y no hacia al delito en términos generales, ya que la visibilidad de la criminalidad está referida a cierta categoría de delitos graves como el homicidio, las lesiones, la violación, el robo a mano armada y el hurto con violencia, (Santos Alvins, 1997) dejando 
por fuera los delitos de cuello blanco y a aquellos que afectan intereses difusos, en tanto no son percibidos comúnmente como constitutivos del fenómeno criminal, dada la selectividad de los procesos de criminalización (Baratta, 1980).

Así, están relacionados con fines individuales y no societarios, referidos a fines más concretos: la protección contra el delito. En consecuencia, corresponden a un tipo de control social instrumental que, por otra parte, no consigue asidero teórico dentro de las concepciones tradicionales del control.

Por ello nosotros recurrimos a tres perspectivas teóricas que aportan algunas pistas para la explicación y tratamiento inicial del fenómeno.

\subsection{La construcción social del miedo}

La realidad en la cual se presenta el delito no es anterior a la experiencia cognoscitiva y práctica, sino construida dentro de esa experiencia a través de la interacción de los individuos o grupos dentro de una sociedad determinada (Baratta, 1986).

El miedo al delito es producto de una construcción social basada, por una parte, en la forma como se definen tanto las situaciones como los sujetos que pueden constituir una amenaza, y por otra, en la forma como son vividas las situaciones de peligro de acuerdo a la pertenencia a un estrato social, que determina la manera de enfrentar la cotidianidad (Cisneros y Zubillaga, 1997).

La construcción social del miedo implica dos niveles de análisis: el vivencial, referido a las condiciones de vida que vinculan a una persona a ciertas situaciones de riesgo y a la experiencia misma del asalto, y el discursivo, que contiene las imágenes y explicaciones a las que se tiene acceso y que configuran la aprehensión-comprensión del fenómeno, en este caso de la violencia delincuencial.

El nivel discursivo estaría determinado por la comunicabilidad de las 
experiencias mediante la conversación cotidiana y por la recepción de mensajes provenientes de los medios de comunicación masiva.

En el proceso se generan ciertas ideas y actitudes en torno a la función policial, en cuanto a la evaluación de su capacidad para garantizar la seguridad de las personas y en cuanto a los espacios en los que la gente considera debe intervenir. De acuerdo con esto, los individuos desarrollan una serie de acciones protectivas, asociadas principalmente al temor de ser víctimas del delito. Estas acciones son consideradas como "anticipaciones de vulnerabilidad".

\subsection{El modelo de Justicia Privada}

Sostiene que la tendencia privatizadora del control (dirigida hacia la protección de bienes y personas al margen de los límites establecidos por el derecho penal) está en función exclusiva de intereses particulares.

Corresponde a una teorización de las tendencias actuales del control social, (Del Olmo, 2000; Gabaldón, 1999; Adamson, 1998; Baratta, 1998). Según este modelo, el ejercicio del control se desplaza del sector público al sector privado como consecuencia de la globalización económica y cultural, la tecnificación del control (mecanismos avanzados de vigilancia) y el desmontaje del Estado benefactor.

En particular, Rosa Del Olmo, incluye a los servicios de seguridad privados dentro de lo que denomina Modelo de Justicia Privada. En muchos aspectos su planteamiento se fundamenta en el trabajo sobre sistemas de seguridad privada realizado por los canadienses Clifford Shearing y Philip Stenning en la década de los '80 (Morais, 1999); que sostiene que la tendencia privatizadora del control (dirigida hacia la protección de bienes y personas al margen de los límites establecidos por el derecho penal) está en función exclusiva de intereses particulares.

El modelo es aplicable principalmente a los servicios de seguridad privada corporativos, que poseen ostensibles diferencias con el esquema 
de seguridad privada informal que adelantan los sectores medios marabinos. Sin embargo, podría constituir una herramienta útil, en cuanto sus explicaciones se derivan de una caracterización del fenómeno de la privatización, que posibilita la contextualización de nuestro objeto de estudio dentro de las nuevas interpretaciones del control social.

En este sentido, el Modelo de Justicia Privada parte de las siguientes precisiones: a) el control ejercido responde a intereses privados; b) el esquema de operación (vigilancia y sanciones) no está circunscrito a los mandatos legales ni a las garantías ciudadanas; prevaleciendo criterios eficientistas sobre la base de los conceptos de riesgo y pérdida, que en ocasiones pueden inducir a la conculcación de derechos ciudadanos; y c) su legitimidad está justificada en normas legalmente establecidas, como la defensa de la propiedad, por lo que es tolerado por el propio Estado.

\subsection{El enfoque situacional del delito}

Desarrollado en Inglaterra y Norteamérica y basado en las propuestas de Clarke y Felson (1993), el Enfoque Situacional plantea el control social del delito a través de un paradigma preventivo que enfatiza el análisis del mismo acto criminal; tomando el delito como una entidad de análisis autónomo.

Las Ilamadas teorías del crimen asumen la necesidad del control social y se preocupan por encontrar formas de control que sean eficaces y a su vez aceptables éticamente. Las teorías del crimen parten del supuesto de que existen personas motivadas a cometer delitos; interesa saber entonces, mediante un estudio situacional, dónde, cuándo y en qué circunstancias estos se cumplen para poder reducir sus oportunidades.

En forma general, el Enfoque Situacional está basado en el análisis de las precauciones rutinarias frente al delito, tales como el uso de alarmas, cerraduras, construcción de murallas o cierre de espacios, evitación de lugares y personas peligrosas, etc., y parte de la idea que la prevención del delito no debe ser exclusiva de las agencias de control formal; sino por el 
contrario, una responsabilidad compartida por toda la sociedad.

Además, entiende el acto criminal como una convergencia de oportunidades, distribuidas social, espacial y temporalmente. La distribución no es aleatoria, pues ocurre en particulares lugares y momentos, teniendo como víctimas u objetivos determinadas categorías de personas y cosas, lo que guarda una estrecha relación con las teorías de los estilos de vida, que sugieren que la distribución del delito puede estar determinada por el nivel de exposición de los individuos a lugares, situaciones o personas peligrosas de acuerdo a un estilo de vida específico. Igualmente, que la pertenencia a un estrato socioeconómico determina una vulnerabilidad diferenciada hacia el acto criminal: las personas con menos recursos económicos ven reducidas sus oportunidades para evitar las situaciones peligrosas y tener acceso a medios de seguridad adecuados.

Así, el control social es entendido básicamente como prevención del delito, por lo tanto interesa construir bases teóricas, fundamentadas en estudios empíricos, que sirvan para el diseño de técnicas y medidas de prevención situacional, controlando las variables que puedan modificar las oportunidades para la comisión de actos criminales.

Dentro de la diferenciación criminológica tradicional del control formal e informal -, el enfoque situacional del delito se considera a sí mismo como una tercera forma, ya que se define como un conjunto de medidas cotidianas que adoptan los ciudadanos o las organizaciones sociales para prevenir su propia victimización (Medina Ariza, 1997).

El Modelo de Prevención Situacional, al igual que el Modelo de Justicia Privada, está sustentado en criterios de eficacia, pero no en términos económicos de riesgo y pérdida, sino en términos de seguridad, de la seguridad como un valor generalizado en la sociedad, como una necesidad humana básica. Propone un modelo preventivo que se aparta de los mecanismos propios del control social, tanto informal como formal.

La prevención situacional se presenta como una alternativa que no pre- 
tende modificar la conducta ni los valores de los individuos hacia actitudes de conformidad, se limita a controlar las circunstancias que, de alguna manera, dan lugar a la ocurrencia de un hecho delictivo, con el propósito de hacer menos accesible y dificultar, sino imposibilitar, su comisión, mediante la implementación de medidas protectivas con el objeto de prevenir la propia victimización. Estas técnicas están referidas al control de las oportunidades delictivas que convergen en tiempo y espacio en función de tres elementos: la presencia de un delincuente motivado, un objetivo alcanzable y la ausencia de un guardián capaz de prevenir, entendiendo por guardián a cualquier persona capaz de intervenir y disuadir al delincuente.

Las contribuciones que estas teorías (Construcción Social del Miedo, Modelo de Justicia Privada y Enfoque Situacional del Delito) pueden dar para la explicación del fenómeno son obvias: el reconocimiento de las precauciones rutinarias como una forma de control social distinta a las categorías de control formal e informal, así como las relaciones establecidas entre los estilos de vida y la pertenencia a un estrato socioeconómico determinado con la distribución social y espacial del crimen. Ellos aportan un piso conceptual importante para el análisis del problema.

\section{El caso de la vigilancia informal}

Como expresa la mayoría de los residentes entrevistados, la decisión de contratar vigilantes informales (guachimanes) la tomó la directiva del condominio para responder a su exigencia de seguridad (de propietarios e inquilinos de los conjuntos privados).

En las entrevistas a presidentes de Juntas de Condominio, 80\% manifestó que para la contratación eran obligatorios los requisitos que el Ministerio del Interior señala a las empresas de vigilancia privada, con excepción de ser "reservista" de las fuerzas armadas nacionales. Es decir, que sus requerimientos básicamente son la experiencia previa en un empleo de la misma naturaleza y el manejo de armas de fuego. Es interesante la 
afirmación del 20\% de ellos acerca de que tales requisitos no son necesarios; pero más relevante aquí es el testimonio de más de la mitad de los guachimanes entrevistados $(54,6 \%)$ acerca de que carecen de conocimientos y destrezas con armamento alguno, lo cual no fue obstáculo para su contratación. A propósito, uno de ellos expresa:

Aquí no me pidieron requisitos. Yo mismo la manejé (la escopeta) sin saberla utilizar... Yo mismo llegaba..., yo no sabía como iba a manejar la escopeta, a mí me la entregaban y yo venía en el baño..., le daba a la palanquita,... 'ésto debe ser para quebrarla'... la quebraba. Yo no fui ni reservista. Yo no he sido reservista. Aquí no es como en otras partes privadas que tiene que ser uno reservista, tiene que saber uno de todo eso. Hasta curso..., pero en las urbanizaciones y edificios muy poco (Pedro).

Es que la selección parece estar más basada en recomendaciones de personas vinculadas a los conjuntos residenciales - propietarios, conserjes, y contratantes sostienen que el problema con las empresas de seguridad es que imponen un sistema de "guardias" - relevo - que impide de que el personal se familiarice con los residentes.

Para la preferencia de la vigilancia informal - guachimanismo -, a lo anterior se le agrega el problema de los costos, pues en la percepción de casi la mitad de los residentes $(47,2 \%)$ resulta más barata; además de que presta una más amplia gama de servicios.

Los responsables del condominio (el presidente o el administrador) actúan como jefes o patrones, sustituyendo a los supervisores de las compañías privadas; (entre los 2 ó 3 guachimanes contratados no existen jerarquías). Ellos - los contratantes - son quienes les fijan las funciones y procedimientos y les asignan las tareas. Sin embargo, esto se complica por cuanto los vecinos tienden a involucrarse, como narra uno de los guachimanes: "Todo el mundo se siente jefe mío aquí. Es el problema de 
los condominios, que ahí todos son jefes. Porque ellos pagan una mensualidad, todos pagan mensualidad, y entonces se sienten con autoridad de mandar a hacer a uno algo..., cualquier cosa" (Pedro).

Tal es la diferencia con el vigilante propiamente dicho (perteneciente a una empresa privada): el cumplimiento de labores que no están directamente asociados a la seguridad, entre las cuales destacan la jardinería, la mensajería y la portería.

Según lo que opinan más de 2 tercios de los vecinos, la función de protección fundamental del guachimán debe ser el control del acceso de los extraños, que es más propia de un portero que de un vigilante en sentido estricto.

\section{Sensación de seguridad y satisfacción}

Como se ha expuesto, por lo general, el guachimán es un individuo sin mucha preparación para el manejo de armas de fuego y que cumple una variedad de labores distintas a la vigilancia. Pese a ello, mayoritariamente los vecinos de los conjuntos privados donde prestan servicio, piensan que su contratación es necesaria y debe ser continuada $(87,8 \%)$ y que garantizan protección $(81,1 \%)$.

Figura 1

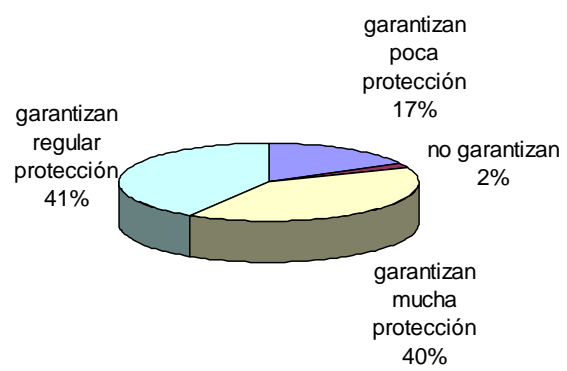

En esto se expresa una sensación de seguridad, basada además en la 
generalizada convicción de los entrevistados $(82,7 \%)$ acerca de que la presencia del vigilante produce la reducción de los delitos. Por lo cual es perfectamente coherente su decisión - en caso de tener que despedir a alguien por razones económicas- de desprenderse del jardinero, conservando al guachimán (90\%). Es que como lo dice uno de éstos: "Nosotros hemos bajado el miedo; porque ellos se sienten más seguros con nosotros. Es más, hay muchas personas ahí que me han dicho, o sea, no es que me estoy alabando... 'Señor Héctor cuando usted está de guardia estamos más tranquilos'"... (Héctor).

El asunto es que, pese a las limitaciones para el cumplimiento de su función, el guachimán dispone de un aceptable equipamiento de armas y de aparatos de comunicación (teléfono, walkie talkie, radio) que unido a la ventaja del acceso restringido - por la existencia en la mayoría de los casos, de una sola entrada con un portón controlado electrónicamente favorece su actividad.

A ello habría que agregar el efecto disuasivo de una persona armada y en plan de protección de las residencias. Tal como relató uno de los vigilantes informales:

Salimos con la escopeta para afuera... No hasta allá, pero hasta el frente con la escopeta... Pasan 2 ó 3 coñitos..., nos ven. Ya esos tienen miedo de meterse. Lo hemos hecho a las dos de la madrugada. Lo hacemos con el fin que se den cuenta que estamos armados (Héctor).

\section{La instrumentalidad: signo distintivo de las nuevas modalidades del control social}

El temor a la violencia, que se origina en las propias vivencias, en las narraciones de la vida cotidiana - particularmente porque quienes han sido victimizados (directa o indirectamente) no han encontrado la adecuada respuesta de los cuerpos policiales y judiciales - y en el trabajo de los 
medios de comunicación acerca de la ocurrencia de hechos delictivos, constituye el dispositivo disparador de los mecanismos de autodefensa desarrollados por la población (cierre de espacios residenciales, afiliación de organizaciones ilegales que ofrecen protección de bienes, etc.). Así, el miedo, que aparece en su base, sería un fenómeno producto de múltiples factores: la victimización, la ineficiencia institucional y la distorsión mediática, principalmente.

Específicamente en las personas entrevistadas, destaca un sentimiento de inseguridad que se funda en la expectativa de ser violentadas en ocasión de los intentos de despojarlas de bienes o dinero, en situaciones que favorecen la acción del hampa: en el estacionamiento de un centro comercial, en un punto de cajero automático y a la salida de una fiesta. De modo que se teme a la calle, pues las propias condiciones de amurallamiento (y de protección por parte de los guachimanes) que han creado, alejan en buena medida las posibilidades de victimización en el entorno residencial.

Las alteraciones en el estilo de vida son evidentes, pues se toman precauciones que afectan la cotidianidad. El esfuerzo por disminuir la exposición personal a la delincuencia incluye la renuncia a la exhibición de joyas y dinero, a la utilización de los dispensadores de dinero en horas nocturnas o en locales de poca afluencia, a la rutina de las caminatas o "trote", a visitar al centro de la ciudad o las salas de cine. Todo con la intención de "desplazar el objetivo" de la delincuencia.

Junto a tales conductas de evitación aparece un conjunto de acciones de protección que implican el blindaje de la vivienda - que se convierte en una "área de refugiados" -; mediante la instalación de toda clase de dispositivos de seguridad (alarmas, rejas, "pérgolas") y la contratación de vigilancia privada. Lo cual repercute en el estilo de vida, en tanto supone la consideración de una nueva partida en el presupuesto familiar: "gastos de seguridad".

En lo referente al servicio de los guachimanes, la efectividad se expresa en la satisfacción que muestran los residentes de las urbanizaciones priva- 
das que custodian. Es que su presencia tiene un efecto disuasivo que se manifiesta tanto en la reducción de las acciones delictivas, como en la seguridad que inspira a sus contratantes. Constituye, por tanto, una modalidad que no corresponde con las formas clásicas del control social, puesto que su propósito es más prevenir situaciones de riesgo que favorecer la cohesión. Lo que la caracteriza es su instrumentalidad.

\section{Referencias}

ADAMSON, G. Posmodernidad y la lógica cultural del capitalismo tardío. Trabajo Presentado en el XI Congreso del Hombre Argentino y su Cultura. Debate sobre los Modelos Culturales a Fines de Siglo. Cordoba, 1998.

BARATTA, A. Criminología y Dogmática Penal. Pasado y Futuro del Modelo Integral de la Ciencia Penal. Papers, Revista de Sociología, n. 13, 1980.

BARATTA, A. Viejas y nuevas estrategias de legitimación del Sistema Penal. Universidad del Zulia, 1986.

BARATTA, A. La política criminal y el Derecho Penal de la Constitución: nuevas reflexiones sobre el modelo integrado de las ciencias penales contemporáneas. Instituto de Criminología. Universidad del Zulia, 1998.

BRICEÑO-LEON, R. Buscando Explicaciones a la Violencia. Espacio Abierto. V. 6, n. 1, 1997.

CISNEROS, A y ZUBILLAGA, B. La Violencia desde la Perspectiva de la Víctima: La Construcción Social del Miedo. Espacio Abierto. V. 6, n. 1, 1997.

CLARKE, R. V. y FELSON, M. (Eds). Routine Activity and Rational Choice. Advances in Criminological Theory. V. 5, 1993.

DEL OLMO, R. Ciudades Duras y Violencia Urbana. Nueva Sociedad, n. 167, 2000 . 
Sociologias, Porto Alegre, ano 4, no 8, jul/dez 2002, p. 136-151

GABALDON, L. G. El Espacio del Control Social Formal en el Mundo Globalizado. In: Homenaje a Fernando Pérez Llantada. Consejo de Publicaciones ULA., Mérida, 1999.

MEDINA ARIZA, J. J. El Control Social del Delito a través de la. Prevención Situacional. Cuadernos de Derecho Judicial, n. 15, 1997.

MELOSSI, P. El Estado del Control Social. Barcelona: Siglo XXI Editores, 1987.

MORAIS, M. G. Servicios de Seguridad en Venezuela (Informe Final). Centro de Investigaciones Jurídicas, UCAB (mimeo), 1999.

PEREZ PERDOMO, R. MALPICA, C. y GONZALEZ, N. Magnitud de la Violencia Delictiva en Venezuela. Espacio Abierto. V. 6, n. 1, 1997.

ROMERO SALAZAR, A. El Ascensor Detenido. La Crisis de la Movilidad Social en Venezuela. Espacio Abierto. V. 8, n. 1, 1999.

ROMERO SALAZAR, A; MOLINA, I; PARRA, A. V. y SALAS, J. Construcción Social del Miedo y Mecanismos de Autodefensa. (Programa de Investigación). Instituto de Criminología. Maracaibo: Universidad del Zulia, 1999.

SANTOS ALVINS, T. Repensando la Violencia desde la Criminología. Espacio Abierto. V. 6, n. 1, 1997. 


\section{Resumen}

En la actual situación de violencia delincuencial, en Venezuela, lo relevante no es el incremento de las tasas sino el aumento de la letalidad de las agresiones. Lo cual se expresa en el aumento de los homicidios y de los robos a mano armada. Tal reforzamiento del contenido violento de la delincuencia se produce en un contexto en el cual el Estado muestra su mayor ineficiencia; tanto en lo atinente al aparato policial (incapacidad para atender las denuncias, procesarlas y capturar a los delincuentes), como al sistema judicial (lentitud y negligencia en la imposición de las penas).

La impunidad propicia que la sociedad se llene de miedo y que la percepción del peligro condicione la vida cotidiana. El estado anímico provocado conduce a la privatización e informalización de la protección, a través de la utilización de diferentes estrategias, entre las cuales destacan el cierre de los espacios residenciales - amurallamiento -, la contratación de vigilantes y, en el caso extremo, la afiliación a organizaciones ilegales que ofrecen seguridad de personas y bienes.

Estas modalidades de protección no pueden ser estudiadas dentro de la concepción clásica del control social; porque no están referidas a una política que toma la prevención en función del ejercicio de un control socializador, en el cual el individuo desviado es considerado como el objetivo principal de la intervención. Más bien, se refieren a la expectativa de la disminución del riesgo de que situaciones relacionadas con la violencia delincuencial afecten la vida privada.

Al respecto, en el artículo se exponen tres enfoques que podrían facilitar la explicación del fenómeno y se ofrecen los resultados de una investigación relacionada con estas nuevas formas de control social.

Palabras-clave: control social, violencia, informalización, privatización del control social. 